\title{
LAS ORACIONES CIRCUNSTANCIALES EN ESPAÑOL
}

\author{
Mario Portilla
}

\begin{abstract}
RESUMEN
Este artículo presenta una propuesta de clasificación de la oraciones circunstanciales del español desde una perspectiva puramente formal. La clasificación tradicional de las oraciones circunstanciales es de índole semántica. Esta incluye nueve clases. La presente clasificación, que es formal, establece solamente dos: relativas y completivas.

Palabras clave: Oraciones circunstanciales o adverbiales, morfosintaxis, español.
\end{abstract}

\begin{abstract}
This article proposes a classification of the adverbial sentences in Spanish from a formal perspective. The traditional classification of adverbial sentences is mainly semantic. This includes nine classes. The proposed classification, which is formal, determines only two: relatives and completives.

Key words: Adverbial sentences, morphosyntax, Spanish.
\end{abstract}

\section{Introducción}

El término oraciones circunstanciales (llamadas también adverbiales) agrupa todo un conjunto semánticamente heterogéneo de cláusulas subordinadas que, dentro de la oración compleja, funcionan de modo semejante a como lo hacen los adyacentes en las oraciones simples. Es decir, se trata de cláusulas subordinadas de una naturaleza semántica muy diversa, que expresan relaciones gramaticales más bien periféricas respecto del verbo de la cláusula principal.

Dr. Mario Portilla. Profesor Catedrático de la Universidad de Costa Rica. San José, Costa Rica. Correo electrónico: marioportilla2000@yahoo.com

Recepción: 17- 4- 2010

Aceptación: 19- 5- 2010 
Por ello, en las gramáticas de índole semanticista (como la gramática normativa de tradición grecolatina, por ejemplo), las oraciones circunstanciales son clasificadas por el contenido o el significado que predican. Un ejemplo paradigmático de este tipo de clasificación es el que ofrecen las Gramáticas normativas del siglo XX de la Real Academia Española. Así, en el Esbozo de una nueva gramática de la lengua española de la Real Academia Española (1973), explícitamente se expresa el criterio semántico que prevalece en la clasificación de este tipo de oraciones. ${ }^{1}$

\footnotetext{
Clasificaremos las oraciones circunstanciales con criterio principalmente semántico. Las denominaciones tradicionales con que las agrupamos y distinguimos unas de otras aluden a la clase de relaciones que por su significado guardan la oración principal del período que forman parte. (Real Academia Española 1973: 536)
}

En esta obra, se reconocen los siguientes tipos de oraciones circunstanciales: de lugar, de tiempo, de modo, comparativas, finales, causales, consecutivas, condicionales y concesivas.

Por otro lado, en las gramáticas formalistas (como las estructuralistas, por ejemplo) se omite clasificar estas oraciones. Un claro ejemplo de esta posición se puede ver en Carratalá (1980), el cual incluso niega la existencia misma de este tipo de oraciones subordinadas.

\footnotetext{
La definición que hace la gramática tradicional en [oraciones subordinadas] sustantivas, adjetivas y adverbiales es una clasificación funcional pese a la terminología, aparentemente formal. No parece que podamos establecer unos tipos morfosintácticos de proposición, ya que ni la forma de estas corresponde sistemáticamente a su función, ni -a diferencia de sustantivos, adjetivos y adverbios-contienen formantes que las caractericen. (Catalarrá 1980: 255)
}

El presente artículo propone una aproximación alternativa a la clasificación semántica de las oraciones subordinadas circunstanciales desde la perspectiva de la teoría funcionalista, tal como ha sido desarrollada especialmente por Talmy Givón (1984, 1990).

\section{Clasificación semántica de las oraciones circunstanciales}

Semánticamente, las oraciones circunstanciales categorizan nociones de lugar, tiempo, modo, comparación, consecuencia, finalidad, causa, concesión y condición.

(01) Ramiro iba a llevarme el encargo [donde yo vivo].

(02) Venga a visitarme [cuando quiera].

(03) Compórtese [como es debido].

(04) Antonio estudia más [que nadie en esta clase].

(05) Era tan brillante [que maravillaba escucharla hablar].

(06) Lo hizo a propósito [para que nos enojáramos].

(07) Actué de esa manera [porque no tenía otra salida].

(08) No hace caso [aunque lo regañen].

(09) Yo también habría ido [si me hubieran invitado].

Las oraciones circunstanciales se suelen clasificar según la noción semántica que exprese en la oración compleja. Las clases de oraciones circunstanciales son las siguientes:

\section{a. Circunstanciales locativas}

Estas cláusulas expresan una circunstancia de lugar semejante a la que desempeñan los adverbios de lugar en las oraciones simples. 
(10) Nos vamos a reunir [donde Cristal].

(11) [A dondequiera que vayas,] yo iré.

(12) No podía mirar [desde donde estaba].

Prototípicamente, las cláusulas locativas van introducidas por el adverbio DONDE. De hecho, formalmente hablando estas construcciones son ciertamente idénticas a las cláusulas relativas sin antecedente que son introducidas por el mismo adverbio relativo DONDE. Así, (13) constituye la versión de (12) simplemente con un antecedente explícito.

(13) No podía mirar desde el lugar [donde estaba].

Otras cláusulas relativas sin antecedente, idénticas a las circunstanciales mencionadas, pueden desempeñar prácticamente otras relaciones gramaticales como argumentos de la cláusula principal.

(14) No me gusta [donde vivo].

La cláusula subordinada anterior es formalmente idéntica a la que aparece en (10). Sin embargo, en (14) la subordinada funciona como sujeto de la oración principal. Y en (10) la subordinada desempeña la función de complemento circunstancial.

\section{b. $\quad$ Circunstanciales temporales}

Estas cláusulas expresan una circunstancia de tiempo que es equivalente a un adverbio de tiempo en una oración simple.

(14) Me echarás de menos [cuando ya no esté contigo].

(15) No lo olvidaré [mientras viva].

(16) Todos salimos [después de que salió Marina].

Por un lado, las circunstanciales temporales van introducidas por adverbios como CUANDO, MIENTRAS, APENAS. En estos casos, las cláusulas son formalmente iguales a las relativas sin antecedente. Esto es evidente al comparar (14) con (17), una relativa con antecedente explícito.

(17) Me echarás de menos en el tiempo [cuando ya no esté contigo].

Por otro lado, estas circunstanciales pueden ser introducidas también por un adverbio y por una preposición, pero seguidos de la conjunción QUE, como en (16) y (18).

(18) No voy al circo [desde que era pequeño].

\section{c. Circunstanciales modales}

Las circunstanciales modales expresan predicaciones que son equivalentes a adverbios de modo en oraciones simples.

(19) Gutiérrez escribió esta carta [como se la dictaron].

(20) Voy a hacerlo todo [según me lo indiquen ustedes].

(21) Ordénelos [conforme vayan llegando]. 
Los adverbios que introducen comúnmente estas circunstanciales son COMO, SEGÚN y CONFORME. Las circunstanciales modales son idénticas a las relativas sin antecedente, como se nota al comparar (19) con (22).

(22) Gutiérrez escribió esta carta del modo [como se la dictaron].

\section{d. Circunstanciales comparativas}

Las circunstanciales comparativas son cláusulas en las que se establece una comparación entre dos términos, uno en la cláusula principal y otro en la cláusula subordinada.

(23) Patricia tiene más paciencia [que un santo].

(24) Marcelo es tan inteligente [como su hermanita].

(25) Por lo menos, hoy llegaste menos tarde [que ayer].

En la cláusula principal, junto a la cualidad comparada, aparece un cuantificador, el cual establece el tipo de comparación. La cualidad comparada se expresa, por lo general, por medio de un adjetivo (24), aunque también puede hacerse a través de un sustantivo (23) o de un adverbio (25).

También, es posible establecer una comparación de cantidad. En estos casos, el cuantificador se relaciona solamente con el verbo conjugado de la cláusula principal.

Yo sé de ese asunto tanto [como ustedes].

La comparación puede ser de igualdad o de desigualdad. La comparación de igualdad se establece con diversos cuantificadores: los adverbios invariables TAN y TANTO, los cuales se relacionan con adjetivos o verbos, y los adjetivos TANTO, TANTA y sus respectivos plurales, los cuales modifican sustantivos. La cláusula subordinada se introduce por medio del completizador СОмО.

(28) Esparta no fue tan importante [como Atenas].

(29) Ya no te quiero tanto [como antes].

(30) Marta dice tantas tonterías [como siempre].

La comparación de desigualdad puede ser de superioridad o de inferioridad. La primera se establece por medio del adverbio MÁs y la segunda a través del adverbio MENOS. En ambos casos, la cláusula subordinada es introducida por el completizador QUE.

(31) Jesús salió más perezoso [que su padre].

(32) Lope de Vega escribió más [que nadie en su época].

(33) Busco a alguien menos quisquilloso [que vos].

Los adjetivos comparativos MEJOR, MAYOR y PEOR, MENOR establecen también comparaciones de superioridad y de inferioridad respectivamente.

(34) Arturo es mejor amigo [que Julio].

(35) Yo bailo peor [que usted]. 
Prototípicamente, en las oraciones comparativas, se suele elidir el verbo en la cláusula subordinada, como se ve en todos los ejemplos anteriores. Sin embargo, a veces puede aparecer un verbo en la cláusula subordinada. En estos casos, la cláusula subordinada es una relativa sin antecedente introducida por el artículo LO. Se une a la principal por medio de la preposición DE.

(36) Usted sabe más [de lo que dice].

(37) Uno debería gastar menos [de lo que gana].

\section{e. Circunstanciales consecutivas}

Las oraciones consecutivas expresan que el evento descrito en la cláusula subordinada es consecuencia de lo que se predica en la cláusula principal.

(38) Estaba tan distraída [que no me escuchó llegar].

(39) Anoche comí tanto [que no pude dormir].

(40) Carlos se metió en tales enredos [que no sabía que hacer].

En la cláusula principal, un cuantificador establece una relación de intensidad que produce la consecuencia expresada en la cláusula subordinada. Los cuantificadores son los adverbios TAN, TANTO, los cuales modifican adjetivos (38) o verbos (39), y los adjetivos TANTO, TANTA, TAL, con sus respectivos plurales, los cuales modifican sustantivos (40).

\section{f. $\quad$ Circunstanciales finales}

Las oraciones circunstanciales finales describen el propósito o finalidad del evento expresado por el verbo de la cláusula principal. Prototípicamente, las subordinadas finales van introducidas por la preposición PARA, acompañada del completizador QUE cuando el verbo de la subordinada va conjugado. También, las cláusulas finales pueden introducirse por otras frases conjuntivas como A FIN DE (QUE).

(41) Compré uvas [para que todos comamos].

(42) Vine [para verte].

(43) Pongámonos de acuerdo [a fin de terminar la reunión].

Las cláusulas finales son claramente instancias de cláusulas completivas que funcionan como complementos circunstanciales. El hecho de que el verbo de la subordinada aparezca conjugado o no depende de que haya una identidad entre el sujeto de la cláusula principal y el de la subordinada.

\section{g. Circunstanciales causales}

Las oraciones circunstanciales causales expresan el motivo o la causa de la predicación que aparece en la cláusula principal. Prototípicamente, las cláusulas causales se unen a la principal por medio de la conjunción PORQUE. También pueden hacerlo a través de otros conectores como PUES, YA QUE, PUESTO QUE. 
(44) Está así [porque le pasó algo].

(45) Lo hice [pues no tenía otra alternativa].

(46) Se durmió de inmediato [ya que estaba muy cansado].

Es evidente que la mayor parte de los conectores que unen la subordinada causal a la cláusula principal están relacionados, en su origen, con el completizador QUE. En este sentido, en su forma, estas cláusulas circunstanciales son muy afines con las subordinadas completivas.

\section{h. Circunstanciales concesivas}

Las oraciones circunstanciales concesivas expresan una objeción a la situación o el evento expresado en la cláusula principal. Esta objeción, sin embargo, no constituye un impedimento para su realización. El conector más prototípico que une la cláusula subordinada con la principal es AUNQUE. Otros conectores que también se utilizan para introducir cláusulas concesivas son AUN CUANDO, A PESAR DE QUE, entre otros.

(47) Todavía tengo esperanzas [aunque no sepa nada de ellos].

(48) Nunca estaré de acuerdo con esto [aun cuando todos lo estén].

(49) No le creo [a pesar de que lo jure].

Al igual que en el caso de las causales, en su origen, ciertos conectores de concesivas están relacionados con el completizador QUE. Igualmente, en su forma, las circunstanciales concesivas son muy semejantes a las subordinadas completivas.

\section{i. $\quad$ Circunstanciales condicionales}

Prototípicamente, las oraciones circunstanciales condicionales expresan una condición o hipótesis que debe cumplirse para que ocurra lo que se predica en la cláusula principal.

(50) Te veo mañana [si todo sale bien].

(51) [Si me preguntan directamente,] voy a decirlo todo.

También, es muy común que estas circunstanciales no expresen una verdadera condición o hipótesis por cumplir (condicionales reales), sino que más bien describan una condición no cumplida (condicionales irreales).

(52) Lo habría hecho [si hubiera tenido más tiempo].

(53) [Si no hubiera llovido], habríamos salido.

Ambos tipos de construcciones condicionales se introducen por medio del conector SI. Además, la frase conjuntiva SI BIEN permite introducir cláusulas condicionales con valor concesivo.

(54) Voy a ir a la fiesta [si bien no estaba seguro de hacerlo].

Por otro lado, hay que admitir que, en muchas ocasiones, las circunstanciales condicionales no introducen una verdadera condición, sino más bien una simple contraposición de términos.

(55) [Si usted está contento con eso], yo no lo estoy.

(56) [Si este corre], el otro vuela. 


\section{Identidad de forma, identidad de significado}

Un principio básico del estructuralismo en lingüística, y por tanto de la teoría gramatical funcionalista, es que dos formas idénticas en funciones equivalentes deben ser consideradas iguales. Del mismo modo, dos formas distintas apuntan necesariamente a significados diferentes.

Este punto se puede ilustrar con el análisis de las oraciones completivas con completizador y con verbo en infinitivo en español.

(01) Juan dijo [que quería ir de vacaciones a la playa].

(02) Juan dijo [querer ir de vacaciones a la playa].

En los ejemplos anteriores, las cláusulas subordinadas son oraciones completivas porque funcionan como un argumento de objeto directo de la cláusula principal. Son, por supuesto, oraciones porque contienen un verbo (conjugado en 01 y en infinitivo en 02).

Las subordinadas deben ser consideradas instancias de cláusulas completivas porque cumplen con una identidad de forma: ambas son oraciones (porque presentan un verbo) y ambas funcionan como el objeto directo de la cláusula principal.

Por otro lado, también es evidente que las dos cláusulas subordinadas completivas de los ejemplos anteriores no son totalmente idénticas en el plano formal: (01) presenta un verbo conjugado y va introducida por el completizador QUE; y (02) aparece con el verbo en infinitivo y unida a la cláusula principal por yuxtaposición. Aunque en un plano meramente denotativo pareciera que la oraciones (01) y (02) significan "lo mismo", la diferencia formal de la presencia o ausencia del completizador, por lo menos, obliga a considerar una distinción en el plano del significado.

En este caso, el principio icónico de la relación entre la integración estructural y la integración conceptual (cf. Payne 1997:181) podría ser aducido como un indicio de la diferencia de significados entre las oraciones mencionadas. Así, es probable que en (01) se exprese un menor compromiso por parte del participante entre lo que expresa en la cláusula principal y la subordinada que en (02). Esto se refleja icónicamente en la mayor distancia entre las dos cláusulas provocada por la inserción del completizador QUE en (01).

Otro de los principios básicos del estructuralismo, que ha sido muy enfatizado por la teoría funcionalista, es una clara distinción en el lenguaje entre los planos formal y semántico. Las categorías linguiísticas que se reconocen en una lengua solo pueden ser consideradas reales cuando se expresan por medio de operadores formales que las distinguen. Las categorías lingüísticas son nociones que trasmiten contenidos abstractos. Pertenecen al plano del significado. Sin embargo, estos significados solo pueden ser identificados porque ciertos operadores gramaticales los señalan de manera consistente. Los operadores gramaticales son marcadores lingüísticos formales, tales como afijos, partículas, perífrasis (o construcciones sintácticas particulares) y lexemas. Estos pertenecen al plano de la forma.

Este punto puede ser ilustrado en la caracterización de los adjetivos como una clase de palabras que no es independiente de la de los sustantivos.

En el nivel semántico, de manera prototípica, por un lado, los sustantivos categorizan entidades (concretas y abstractas): sol, muchacho, día, verdad. Por otro lado, los adjetivos, prototípicamente, categorizan cualidades: verde, grande, grueso, joven. Es evidente que, a nivel abstracto, los sustantivos y los adjetivos significan "cosas distintas". 
En el nivel formal, sin embargo, hay que reconocer que los sustantivos y los adjetivos presentan una morfología flexiva prácticamente idéntica. Por ejemplo, presentan los mismos operadores de género y número. Además, si bien es cierto que sintácticamente los sustantivos funcionan, de manera prototípica, como núcleos de frases nominales (03) y los adjetivos lo hacen como modificadores (05). También, es innegable que los sustantivos intercambian estas funciones de forma muy frecuente. Así, encontramos adjetivos funcionando como núcleos de frases nominales (04) y sustantivos como modificadores (06).

Núcleo de FN

(03) Los muchachos ya se fueron. Muchacho = Sustantivo

(04) Los jóvenes ya se fueron. Joven = Adjetivo

\section{Modificador}

(05) Los hombres jóvenes ya llegaron. Joven = Adjetivo

(06) Los hombres rana ya llegaron. Rana $=$ Sustantivo

De tal modo, dado que los sustantivos y los adjetivos presentan una identidad innegable en el plano morfosintáctico (es decir, formalmente), es necesario reconocer que constituyen una única y misma clase de palabras en español, a pesar de que se pueda decir que semánticamente expresen nociones distintas. Por ello, se puede afirmar que los sustantivos y los adjetivos pertenecen, en realidad, a una sola clase, la de los nombres.

\section{Las subordinadas circunstanciales: Cláusulas relativas o cláusulas completivas}

Desde una perspectiva puramente formal, se pueden distinguir en español solamente dos clases de cláusulas subordinadas claramente distintas: completivas y relativas. Tradicionalmente, estas se denominan también subordinadas sustantivas y subordinadas adjetivas respectivamente.

Precisamente, al igual que lo hacen prototípicamente los sustantivos como núcleos en las oraciones simples, las cláusulas completivas tienen la función de servir de argumentos de la cláusula principal en las oraciones complejas. Los argumentos que desempeñan son especialmente de sujeto (01), (03) y de objeto directo (02), (04). ${ }^{2}$

(01) Me alegra [que todo haya salido bien].

(02) Quisiera [que no me llamaras a diario].

(03) [Hacer ejercicio] es saludable.

(04) Pienso [volver a mi país].

Por su parte, como los adjetivos, las cláusulas relativas funcionan como un modificador de un núcleo nominal, denominado el antecedente (subrayado en los ejemplos siguientes).

(05) La película [que fuimos a ver] estuvo buenísima.

(06) El problema [del cual estuvimos hablando] no se va resolver pronto.

(07) Los adverbios, [que son una clase de adyacentes,] son invariables.

(08) Te presento a Raúl, [quien juega en el Real]. 
Como se ha dicho, en español, al igual que sucede con los sustantivos y los adjetivos, en ciertas ocasiones es difícil distinguir incluso entre una completiva y una relativa, dado que o bien la completiva funciona como un modificador nominal (09 y 10) o bien una relativa sin antecedente funciona prácticamente como el argumento de la cláusula compleja $(11,12)$.

Cláusulas completivas que funcionan como modificador nominal

(09) Nos conmovió la noticia de [que hubiera muerto tu padre]

(10) No me gusta la idea de [ir todos juntos].

\section{Cláusulas relativas sin antecedente}

(11) [Quien sale de último] apaga la luz.

(12) Deploro [lo que pasó].

Además, es también significativo que, de manera prototípica, se utilice la conjunción QUE como operador de subordinación tanto en las completivas como en las relativas (cf. 01 y 05). ${ }^{3}$

A pesar de todo, se debe admitir que las completivas y las relativas son dos tipos de cláusulas subordinadas distintas, especialmente por su relación de dependencia respecto de un núcleo en la cláusula principal. Desde un punto de vista formal, las cláusulas completivas dependen del verbo de la cláusula principal y las relativas lo hacen de un núcleo nominal o sustantivo.

Ahora bien, en el caso de las oraciones subordinadas circunstanciales, ha quedado claro que, desde una perspectiva semántica, estas expresan situaciones que se consideran más bien periféricas respecto de la predicación del verbo, al igual que lo hacen los adyacentes (adverbios o frases preposicionales) en las oraciones simples.

Sin embargo, desde una perspectiva formal, las circunstanciales o bien son idénticas a las cláusulas relativas o bien lo son a las cláusulas completivas. Es decir, las subordinadas circunstanciales no podrían ser consideradas una clase aparte de subordinadas, sino una subclase, si se quiere, de las completivas o de las relativas.

\section{Clasificación formal de las subordinadas circunstanciales}

\subsection{Circunstanciales que son cláusulas relativas}

Las oraciones subordinadas circunstanciales locativas, temporales, modales, comparativas y consecutivas son muy similares formalmente a las subordinadas relativas. Estas oraciones comparten la particularidad de ser semejantes a las cláusulas relativas, en cuanto todas presentan un elemento antecedente en la cláusula principal con el cual están relacionadas.

En el caso de las locativas, temporales y modales, lo que sucede es que se trata de relativas en las que, a todas luces, el antecedente ha sido elidido por su baja referencialidad. Es decir, corresponden a las llamadas cláusulas relativas con antecedente callado.

\section{Circunstancial locativa}

(01) No me gusta [donde vivo] $\quad<=$ No me gusta el lugar [donde vivo].

\section{Circunstancial temporal}

(02) No me gusta [cuando llueve] $<=$ No me gusta el tiempo [cuando llueve]. 


\section{Circunstancial modal}

(03) No me gusta [como cantás] $<=$ No me gusta el modo [como cantás].

En los casos de las comparativas y las consecutivas, explícitamente aparece un antecedente en la cláusula principal con el cual se la relaciona la oración subordinada. Por un lado, en las oraciones comparativas, prototípicamente, se establece una relación de comparación de una cualidad entre dos elementos nominales, uno en la cláusula principal y otro en la subordinada, el cual representa la norma o estándar de la comparación.

(04) Andrés es más alto [que su hermano mayor].

En el ejemplo anterior, ANDRÉs y SU HERMANO MAYOR son los elementos nominales y ALTO es la cualidad comparada. La cualidad comparada es el elemento en la cláusula principal que sirve de antecedente de la cláusula subordinada. Por decirlo así, es el elemento que se relativiza. Precisamente, por ser idéntico en ambas cláusulas, este se omite en la subordinada, por lo general.

(05) Andrés es tan alto [como su hermano mayor (es alto)].

Como se ha dicho antes, la comparación se establece no solo entre elementos nominales ni solo se comparan cualidades expresadas por adjetivos. Sin embargo, la presencia de un antecedente de la cláusula principal en la subordinada siempre está implícita. Este hecho hace que estas cláusulas deban ser consideradas un tipo de relativas.

(06) Patricia tiene más paciencia [que un santo (tiene paciencia)]

(07) A Emilia le gusta más tomar el sol [que nadar (le gusta a Emilia)].

En el caso de las comparativas en las que no se elide el elemento idéntico de la cláusula principal en la subordinada es aún más claro de que se trata de una cláusula relativa sin antecedente. El antecedente se omite por ser poco referencial.

(08) Usted sabe más $\varnothing$ [de lo que dice]. $\Leftarrow$ Usted sabe más cosas [de las que dice].

(09) Uno debería gastar menos $\varnothing$ [de lo que gana]. <= Uno debería gastar menos dinero [del que gana].

Por otro lado, como se ha dicho, en las circunstanciales consecutivas, aparece un cuantificador de intensidad en la cláusula principal que produce la consecuencia expresada en la cláusula subordinada. El cuantificador prototípico (aunque no exclusivo) es el adverbio (y adjetivo) TANTO (con sus variantes TAN, TANTA).

En la cláusula principal, un cuantificador establece una relación de intensidad que produce la consecuencia expresada en la cláusula subordinada.

(10) Mario estudió tanto [que se durmió].

(11) Alejandro es tan perfeccionista [que nunca termina nada].

(12) Vino tanta gente a la conferencia [que no cabía en la sala].

Precisamente, este cuantificador es el que funciona como antecedente de la cláusula subordinada en la cláusula principal. Como suele suceder en las relativas, este antecedente se omite en la cláusula subordinada. Sin embargo, siempre se halla presente implícitamente. 
Esto se puede notar cuando este elemento es explicitado en la cláusula subordinada, como se observa en los ejemplos (13, 14 y 15) que son las versiones correspondientes de (10, 11 y 12).

(13) Mario estudió mucho/tanto [por tanto se durmió].

(14) Alejandro es muy/tan perfeccionista [por tanto nunca termina nada].

(15) Vino mucha/tanta gente a la conferencia [por tanto no cabía en la sala].

Así, pues, tanto en oraciones locativas, temporales y modales como en las comparativas y consecutivas, se establece un antecedente del cual depende la cláusula subordinada. Como se dicho, la existencia de tal antecedente es lo que define más esencialmente la relación de subordinación relativa desde una perspectiva formal. Por tanto, hay que concluir que estas oraciones subordinadas son tipos de cláusulas relativas.

\subsection{Circunstanciales que son cláusulas completivas}

Las oraciones subordinadas circunstanciales finales, causales, concesivas y condicionales son muy afines en su forma con las subordinadas completivas. Esto es evidente, por ejemplo, por la presencia recurrente del completizador QUE, el cual sirve de nexo subordinador prototípico que une la cláusula principal con la subordinada, con excepción de las oraciones condicionales.

(16) El profesor dijo [que el examen fue éxito].

Completiva en función de objeto directo

(17) El profesor dijo esto [para que los estudiantes no se preocuparan].

\section{Circunstancial final}

(18) El profesor dijo esto [porque tuvo lástima de los estudiantes].

Circunstancial causal

(19) El profesor dijo esto [aunque fuera mentira].

Circunstancial concesiva

(20) El profesor no habría dicho esto [si no le hubieran preguntado].

Circunstancial condicional

Como se ha dicho, la función prototípica de las cláusulas completivas es la de servir de argumento de sujeto o de objeto directo del verbo de una cláusula principal. Obviamente, todas estas circunstanciales no funcionan como argumentos (es decir, no tienen una relación de dependencia relevante respecto del verbo), sino más bien como adyacentes (es decir, su relación respecto del verbo es más bien periférica). Por ello, no se han clasificado tradicionalmente como subordinadas sustantivas.

Sin embargo, hay que mencionar que ciertas completivas, reconocidas como tales tradicionalmente, también desempeñan otras relaciones gramaticales que no corresponden a argumentos. Tal es el caso de las completivas que funcionan como atributos (21), complementos verbales (22) y complementos nominales (23). 
(21) El secreto está [en que lo haga despacio].

(22) Sueño [con que haya paz en el mundo].

(23) Estoy triste [de que te vayás].

En estos tres casos, las cláusulas completivas no funcionan como argumentos propiamente dichos. Sin embargo, se consideran instancias de cláusulas completivas especialmente por su forma (en este caso son introducidas por el completizador QUE) y porque funcionan como un sustantivo. Es decir, funcionan como frases nominales.

Otro aspecto significativo que se observa en las cláusulas completivas anteriores es que estas van precedidas de una preposición. Esto muestra que, de nuevo, las cláusulas completivas funcionan como frases nominales, pues estas constituyen los núcleos de frases preposicionales.

Como se ha visto en el apartado 2, es común que las subordinadas circunstanciales de este segundo grupo sean introducidas también por preposiciones o frases nominales que contienen preposiciones. De hecho, por ejemplo, la forma canónica de nexo subordinador de circunstanciales causales PORQUE proviene evidentemente de la preposición POR seguida del completizador QUE.

Otro aspecto que muestra la identidad entre las completivas y este segundo tipo de circunstanciales es el hecho de que las finales, causales y concesivas presentan un verbo en infinitivo en las mismas condiciones en que lo hacen las completivas. En general, esto sucede sobre todo a consecuencia de la elisión del sujeto en la cláusula subordinada porque es idéntico al sujeto de la principal.

(24) Creo que [ustedes son felices].

\section{Completiva con verbo conjugado}

(25) Creo [ser feliz].

\section{Completiva con infinitivo}

(26) Compré esta entrada [para que vayamos al cine juntos].

Circunstancial final con verbo conjugado

(27) Compré esta entrada [para ir al cine solo].

Circunstancial final con infinitivo

(28) Lo hice [porque quiero salir adelante].

Circunstancial causal con verbo conjugado

(29) Lo hice [por salir adelante].

Circunstancial causal con infinitivo

(30) No le creo [a pesar de que lo jure].

Circunstancial concesiva con verbo conjugado

(31) No le creo [a pesar de jurarlo].

Circunstancial concesiva con infinitivo 
El hecho de que las subordinadas completivas y las circunstanciales puedan aparecer con el verbo en infinitivo muestra que estas son muy afines a los sustantivos, ya que precisamente los infinitivos pueden ser considerados una subclase de los nombres.

Por último, al igual que se ha dicho para el caso de las circunstanciales finales, causales y concesivas, las condicionales son construcciones muy afines con las subordinadas completivas, en el aspecto formal.

Es interesante señalar, en este sentido, que existe un paralelismo en el uso de los completizadores QUE, que introduce completivas, y SI, que sirve para introducir protípicamente las condicionales. Esta semejanza se nota claramente en el caso del discurso indirecto.

(32) Pablo dijo [que todo andaba bien].

(33) Pablo preguntó [si todo andaba bien].

Evidentemente, QUE se utiliza para introducir proposiciones declarativas y si para el caso de las interrogativas indirectas. En ambos casos, se trata de cláusulas completivas, ya que ambas funcionan como argumentos de objeto directo.

En resumen, las subordinadas circunstanciales finales, causales, concesivas y condicionales forman una subclase de cláusulas completivas, pues son formalmente idénticas a estas y funcionan fundamentalmente como frases nominales.

\section{Núcleos y modificadores}

Aunque desde el punto de vista estructural los sustantivos y los adjetivos deben ser clasificados dentro de una misma clase, la de los nombres, desde una perspectiva distribucional, los sustantivos y los adjetivos se caracterizan por funcionar más prototípicamente como núcleos de frases nominales (los primeros) o como modificadores (los segundos).

En el nivel de las cláusulas, sucede algo semejante con los adyacentes. En las cláusulas simples, los adverbios de lugar, tiempo y modo son adyacentes que tienen una función más de modificadores y, se dice, se relacionan en la cláusula más directamente con el verbo (o con un adjetivo).

En español, la función modificadora de los adverbios, afín a la de los adjetivos, se puede ilustrar con el caso de los adverbios de modo. Tanto sincrónica como diacrónicamente (provienen de nombres adjetivos), los adverbios de modo están relacionados con los adjetivos. ${ }^{4}$

$$
\begin{aligned}
& \text { Hombre rápido. Sustantivo }+ \text { Adjetivo } \\
& \text { (Él) corría rápido. Verbo }+ \text { Adverbio }
\end{aligned}
$$

La identidad que existe entre un adverbio de modo y un adjetivo es evidente. Las diferencias formales entre ambas clases (o subclases de la misma categoría, habría que decir) son fundamentalmente dos. Por un lado, los adjetivos concuerdan en género y número con el sustantivo del cual dependen (cf. Mujeres rápidas) y los adverbios no lo hacen (cf. Ella corría rápido). Por otro lado, los adjetivos establecen una relación de dependencia con los nombres y los adverbios lo hacen con los verbos.

Sin embargo, de forma notable, en ciertas ocasiones los adjetivos (o esta clase de palabras que engloba a adjetivos y a adverbios) modifican tanto a sustantivos como a verbos a la vez. Este es el caso de los llamados predicados conjuntos, en los cuales el adjetivo-adverbio 
concuerda en género y número con un sustantivo de una frase nominal y a la vez establece una modificación del verbo en la frase verbal (15).

\section{(15) María salió contenta del examen.}

Por otro lado, también como adyacentes, las frases preposicionales son más afines a los nombres sustantivos. Desde el punto de vista diacrónico, las preposiciones provienen de nombres. ${ }^{5}$ Igualmente, los núcleos de las frases preposicionales son nombres.

Además, las frases preposicionales como complementos circunstanciales, por ejemplo, no se relacionan tan directamente con el verbo (o con un adjetivo, como lo hacen los adverbios). Esta independencia semántica se refleja a nivel formal por el hecho de que las frases preposicionales pueden colocarse más libremente dentro de la cláusula.

Por ello, no es extraño que las subordinadas circunstanciales, que funcionan como adyacentes en una cláusula compleja, no tengan autonomía formal, pues tampoco la tienen los adverbios ni las preposiciones en las frases preposicionales, que son adyacentes en cláusulas simples.

Así, por un lado, las circunstanciales locativas, temporales, modales, comparativas y consecutivas, como instancias de cláusulas relativas tienen una función modificadora, muy afín a la clase de los nombres adjetivos. Por otro lado, las circunstanciales finales, causales, concesivas y condicionales, como tipos de cláusulas completivas, tienen una función más nuclear, muy afín a la clase de los nombres sustantivos.

\section{Notas}

1. En la edición inmediatamente anterior al Esbozo de 1973, la Gramática de la lengua española de 1931, la cual está a su vez basada en la Gramática de la lengua castellana de 1920 y esta en la de 1917, la Real Academia presenta un capítulo completo con la clasificación y descripción de las oraciones adverbiales, las cuales, señala, funcionan como puede hacerlo un adverbio o una locución equivalente. Serán, pues, tantas como sean las clases de adverbios (Real Academia 1931: 377).

2. También, es posible que una subordinada completiva funcione como argumento de objeto indirecto: No le presto atención a [que me digan loco] (cf. Alarcos Llorach 1994).

3. Portilla (2002) señala el carácter no anafórico que tiene el operador QUE cuando funciona como un relativizador que introduce cláusulas completivas. Afirma que, por tanto, este operador no puede ser considerado un pronombre relativo, como se suele afirmar en la gramática tradicional del español.

4. En general, se podría afirmar lo mismo de los adverbios de lugar y de tiempo. Diacrónicamente, provienen de nombres. Considérense los siguientes ejemplos: ARRIBA < latín ad ripam "a la orilla del río"; encima < "en + cima"; HOY < latín hoc die "este día"; MAÑANA < latín vulgar (cras) maneana "(mañana) temprano" (Gómez de Silva 1985).

5. Un ejemplo todavía evidente del origen nominal de las preposiciones es la preposición BAJo, la cual proviene del latín tardío bassus "gordo, bajo" (Gómez de Silva 1985). Este adjetivo proviene de un nombre propio latino Bassus. Preposiciones compuestas más modernas reflejan el mismo mecanismo de creación a partir de nombres: en frente de, encima de (< en cima), a la par de. 


\section{Bibliografía}

Alarcos Llorach, Emilio. 1994. Gramática de la lengua española. Madrid: Espasa-Calpe.

Carratalá, Ernesto. 1980. Morfosintaxis de castellano actual. Barcelona: Labor.

Givón, Talmy. 1984. Syntax: A functional-typological introduction. Volumen 1. Amsterdam/ Filadelfia: John Benjamins.

1990. Syntax: A functional-typological introduction. Volumen 2. Amsterdam/ Filadelfia: John Benjamins.

Gómez de Silva, Guido. 1985. Breve diccionario etimológico de la lengua española. México: Fondo de Cultura Española.

Payne, Thomas. 1997. Describing morphosytax: A guide for field linguistics. Cambridge: Cambridge University Press.

Portilla, Mario. 2002. "Estrategias de representación de la frase nominal relativizada en español”. Revista de Filología y Lingüística. 28(2): 155-159.

Real Academia Española.1920. Gramática de la lengua castellana. Madrid: Perlado, Páez y Compañía.

1931. Gramática de la lengua española. Madrid: Espasa-Calpe.

1973. Esbozo de una nueva gramática de la lengua española. Madrid: Espasa. 